\title{
Spontaneous recovery of the joint space in degenerative hip disease
}

\author{
G. H. PERRY, M. J. G. SMITH, AND C. G. WHITESIDE \\ From the Departments of Rheumatology and X-Ray Diagnosis, Middlesex Hospital, London, W.1
}

Recovery of the joint space in degenerative hip disease after osteotomy has been described on several occasions and the literature includes reports by Adam and Spence (1958), Nissen (1963), and Harris and Kirwan (1964), but there is much less documentation on spontaneous recovery of the joint space, which forms the subject of this paper.

Danielson (1964) reported real or apparent regression of arthritic changes in eight cases of coxarthrosis and in two of these he demonstrated 'the joint space changes to have regressed', though this was on the basis of only two $x$-rays over a 10 -year period.

Seifert, Whiteside, and Savage (1968) suggested recovery of the joint space in two hips with osteoarthrosis in a 5-year follow-up of 44 patients. Storey and Landells (1971) published a case report showing reformation of the femoral head and reappearance of the radiological joint space.

The purpose of this study is to present fourteen hips showing osteoarthrosis with cystic change in which definite or probable recovery of the joint space occurred.

\section{Materials and methods}

The patients were selected from the 'Research Hip Clinic' at the Arthur Stanley Institute (later Arthur Stanley House of the Middlesex Hospital). This clinic was initiated in 1961 as a 10-year prospective study into the natural course of primary osteoarthrosis. The study was completed in 1970 . Only patients with a normal erythrocyte sedimentation rate, a negative latex test, and a radiological grade of II or more, according to the criteria of Kellgren and Lawrence (1957), were admitted to this study. Patients were seen yearly after their initial visit.

Only patients with radiological cystic changes have been included in this paper. Some had also been observed both before and after the period covered by the hip clinic, so that they had a minimum follow up of 5 years and a maximum of 14 years; 28 patients ( 31 hips) remained from the 44 patients (65 hips) followed for prognostic factors by Seifert and others (1968). It was shown that 90 per cent. of hips with non-cystic disease either remained static or deteriorated only minimally; accordingly, seventeen hips

Accepted for publication May 2, 1972 with no evidence of cyst formation were excluded. Further losses to follow-up reduced the remaining 48 hips to the 31 which are described in this paper.

Films were taken at each attendance, the patient being in the supine neutral position and the $x$-ray beam being vertical. The findings of Arden (1957) and Hirsch (1960) showed the importance of constant radiographic and patient positional factors and we have tried to keep to a minimum the inevitable positional variation which must occur when a fixed deformity develops.

We also noted that films taken in the abduction position gave an apparent increase in joint space, and films taken in abduction were therefore excluded. For obvious reasons films of poor radiographical quality were excluded.

The clinical parameters used were pain, analgesic intake, range of movement, body weight, and the incidence of Heberden's nodes.

Analgesic intake was regarded as minimal if aspirin, codeine, or paracetamol were taken at a dose of two or less tablets daily. Range of movement was converted from a percentage of normal to give a result on a scale from 0 (no movement) to 3 (full movement). Each modality of movement was assessed in this way and an average was then calculated for each hip given as a single value.

The patients were then weighed at each visit and an average so obtained was expressed as a percentage of their ideal weight (Kemsley, 1952).

\section{Results}

Review of the $x$-rays indicated that some patients showed stabilization of the hip and recovery of the joint space. Such recovery, though by no means complete, appeared to depend on the establishment of adequate upper and lower pole 'retaining' osteophytes.

\section{$x$-RAY FINDINGS}

Two main groups were distinguished. The first (4 males, 10 females) showed recovery of joint space and stabilization of the hip and was designated 'The Joint Space Recovery Group', and the second (1 male, 8 females) showed progressive deterioration and was designated 'The Progressive Group'. Of the fourteen hips in Group I, seven were entered as 'probables 
only' because of incomplete follow-up. Of these seven patients who were lost to follow-up, three died, two became infirm, and one moved to another area. Eight of the 31 hips studied did not fit into either group and are not included here.

It is not our purpose to discuss aetiology in detail, but the hips were classified in accordance with recent work using the criteria of Murray (1965) (see Table I). It was considered that ten of these hips showed acetabular dysplasia, and seven showed a varus tilt deformity. One patient had a history of trauma, leaving five hips in the so called 'idiopathic group'; these were all in females which raises the possibility of a basic inflammatory aetiology. Whether the degenerative hip is primary or secondary, however, does not seem to affect recovery.

All our patients showed cystic changes in the femoral head with distortion of the trabecular architecture accompanied by a varying degree of narrowing of the radiological joint space. In some cases cysts and altered trabecular pattern were also present in the acetabular margin.

In Group I the early natural course was generally one of increasing bone destruction with cyst formation and further loss of joint space. During this time, however, upper and lower osteophytes were noted to be forming. Once these retaining osteophytes were established, regression occurred and cyst formation was less obvious, and this was often initially accompanied by increased sclerosis. The radiological joint space then gradually recovered, with some restoration of normal bony trabecular pattern.
Group II differed in that the cystic changes progressed steadily. Osteophyte formation, particularly at the upper pole, was either inadequate or, if it occurred, the osteophyte snapped off and subsequently did not reform. There was a tendency, to a greater or lesser extent, for lateral subluxation of the femoral head to occur with increasing bone destruction.

\section{Illustrative cases}

HIP 1

Fig. 1 (1957) shows the upper joint space to be narrowed; cysts are present and there is an upper pole retaining osteophyte.

Fig. 2 (1960) shows that the upper pole osteophyte has broken off, the joint space is considerably narrowed, and some lateral subluxation has occurred. New bone formation is present medially.

By 1963 (Fig. 3) further subluxation of the head has taken place and the cysts have increased in numbers.

Fig. 4 (1967) shows the upper osteophyte to have re-formed. The cysts are less marked and sclerosis is a little more extensive. The joint space shows initial signs of recovery.

Figs 5 and 6 (1970 and 1971) show progressive increase in the joint space and some restoration of bony architecture.

\section{HIP 4}

Fig. 7 (1965) shows marked cystic destruction of the femoral head, but extensive osteophyte formation is present. Over the next 2 years the joint space showed recovery though considerable cyst formation was still

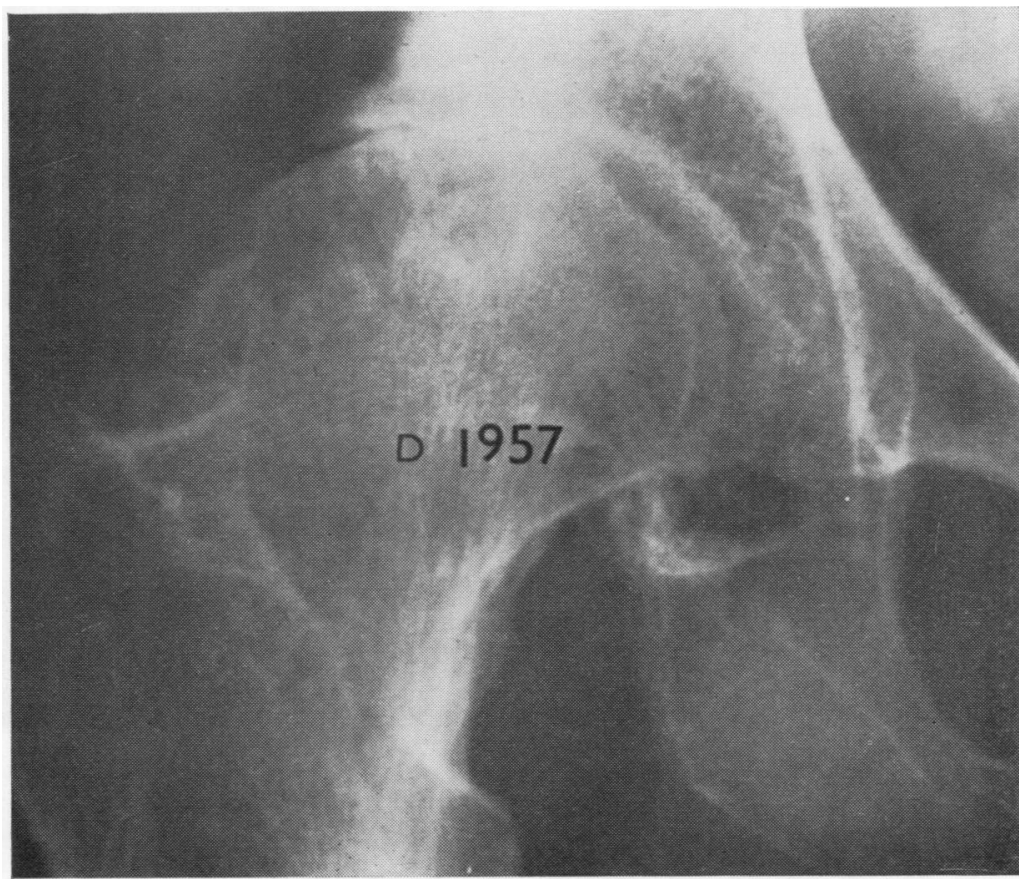

FIG. 1 Hip 1 


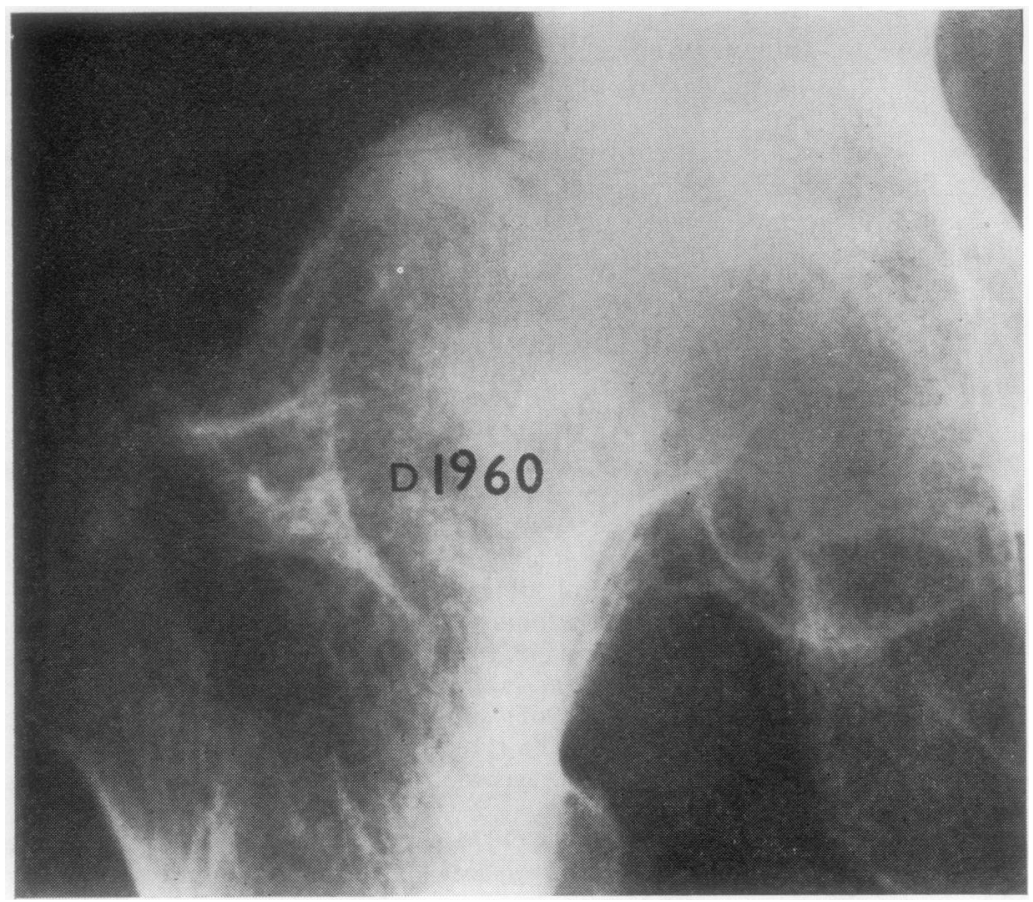

FIG. 2 Hip 1. Note detached upper pole osteophyte

\section{1963}

FIG. 3 Hip 1

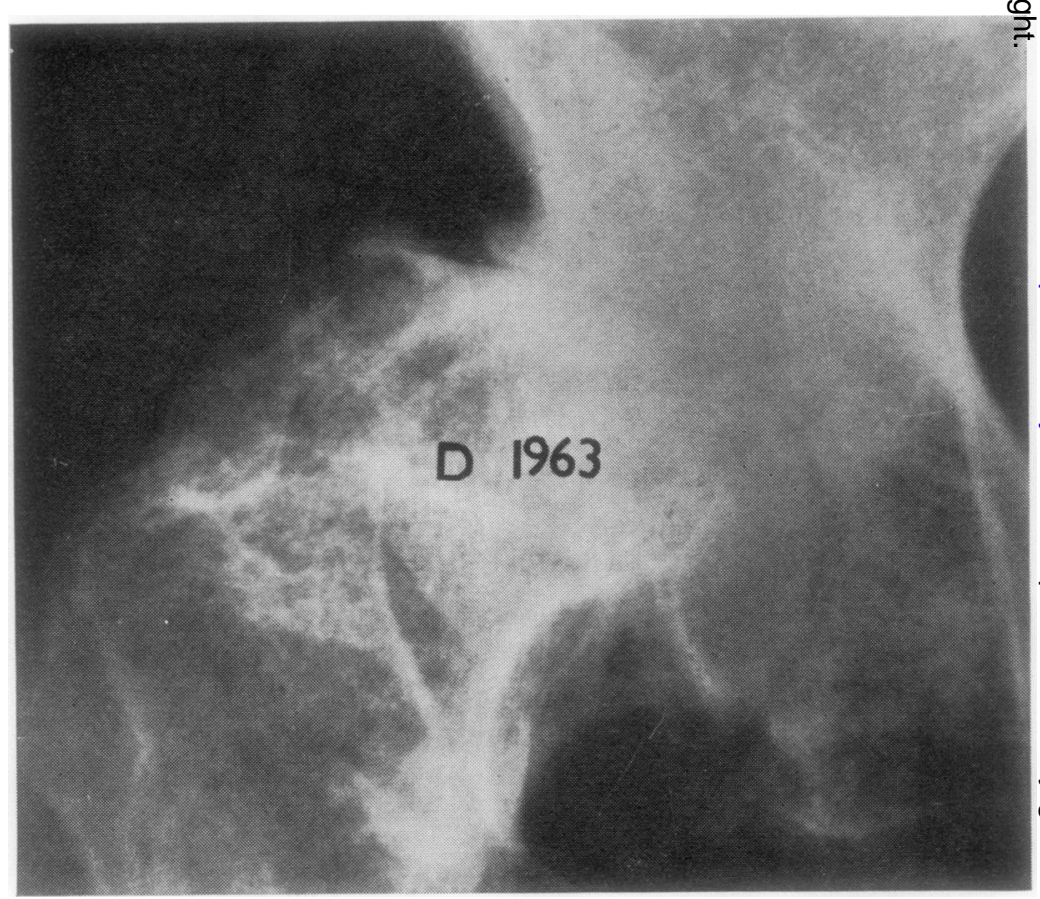

present. By 1970 (Fig. 8) only minimal cyst formation is noted and again there has been some restoration of normal bony trabecular pattern, though in this case a degree of marginal sclerosis is still present.
HIP 13

This patient was one of the seven with probable restoration of joint space. The follow-up period ( 5 years) was short. The film taken in 1960 (Fig. 9) shows considerable 
FIG. 4 Hip 1. Upper pole osteophyte now reformed

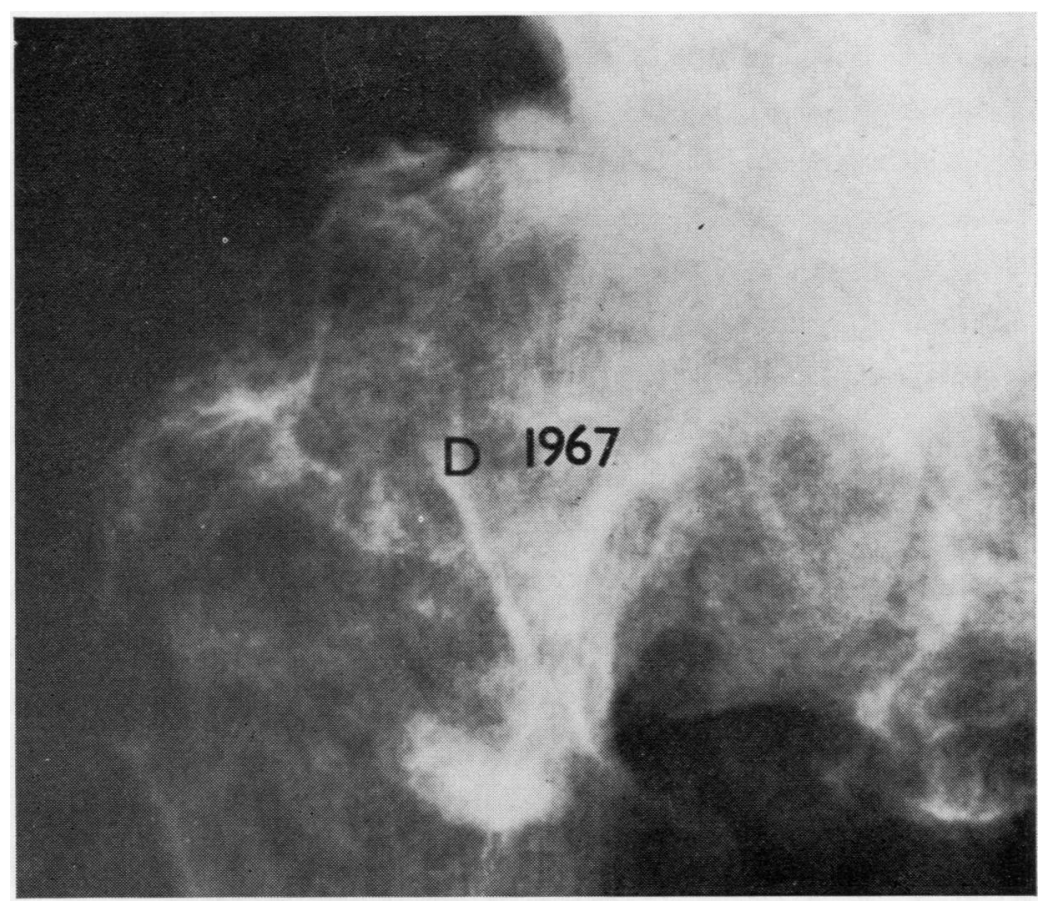

cystic change, particularly supero-laterally. The joint space is markedly reduced but upper and lower pole osteophyte formation is present. By 1962, the retaining osteophytes were well established, and the following year there seemed to be a little increase in joint space with some regression of the cystic change. Increased sclerosis was noted. In 1964 (Fig. 10) the joint space looked to have recovered, but unfortunately the series ended here.

\section{CLINICAL FINDINGS}

The average age at onset of symptoms (Table I) was similar (Group I 59 years; Group II 56 years).

\section{Table I Cases studied}

\begin{tabular}{|c|c|c|c|c|c|c|c|c|}
\hline $\begin{array}{l}\text { Hip } \\
\text { no. }\end{array}$ & Group & & $\operatorname{Sex}$ & Aetiology & $\begin{array}{l}\text { Wt per cent. } \\
\text { of ideal }\end{array}$ & $\begin{array}{l}\text { Heberden's } \\
\text { nodes }\end{array}$ & $\begin{array}{l}\text { Age at onset } \\
\text { symptoms (yrs) }\end{array}$ & $\begin{array}{l}\text { Time from onset } \\
\text { to recovery (yrs) }\end{array}$ \\
\hline $\begin{array}{l}1 \\
2 \\
3 \\
4 \\
5 \\
6 \\
7\end{array}$ & $\begin{array}{l}\text { I. Recovery } \\
\text { of joint space }\end{array}$ & Definite & $\begin{array}{l}F \\
F \\
F \\
F \\
F \\
M \\
F\end{array}$ & $\begin{array}{l}\text { Dysplasia } \\
\text { Varus tilt } \\
1^{\circ} \\
1^{\circ} \\
\text { Dysplasia } \\
\text { Dysplasia } \\
\text { Dysplasia }\end{array}$ & $\begin{array}{r}+15.1 \\
+16.7 \\
+17.5 \\
+9.2 \\
+15.2 \\
-\quad 2.3 \\
-1.8\end{array}$ & $\begin{array}{l}0 \\
0 \\
+ \\
0 \\
+ \\
+ \\
0\end{array}$ & $\begin{array}{l}55 \\
51 \\
57 \\
65 \\
68 \\
53 \\
58\end{array}$ & $\begin{array}{r}10 \\
7 \\
10 \\
9 \\
10 \\
12 \\
19\end{array}$ \\
\hline $\begin{array}{r}8 \\
9 \\
10 \\
11 \\
12 \\
13 \\
14\end{array}$ & & Probable & $\begin{array}{l}F \\
F \\
F \\
M \\
M \\
F \\
M\end{array}$ & $\begin{array}{l}\text { Trauma } \\
\text { Varus tilt } \\
\text { Dysplasia } \\
\text { Varus tilt } \\
\text { Varus tilt } \\
1^{\circ} \\
\text { Varus tilt }\end{array}$ & $\begin{array}{l}+12 \cdot 7 \\
-5 \cdot 4 \\
+22 \cdot 3 \\
+4.6 \\
-10 \cdot 2 \\
-\quad 5 \cdot 0 \\
+13 \cdot 0\end{array}$ & $\begin{array}{l}+ \\
0 \\
0 \\
0 \\
+ \\
+ \\
+\end{array}$ & $\begin{array}{l}51 \\
67 \\
71 \\
43 \\
57 \\
64 \\
61\end{array}$ & $\begin{array}{r}9 \\
6 \\
11 \\
5 \\
9 \\
6 \\
15\end{array}$ \\
\hline $\begin{array}{l}15 \\
16 \\
17 \\
18 \\
19 \\
20 \\
21 \\
22 \\
23\end{array}$ & II. Progressive & & $\begin{array}{l}F \\
F \\
F \\
F \\
F \\
F \\
M \\
F \\
F\end{array}$ & $\begin{array}{l}\text { Dysplasia } \\
1^{\circ} \\
\text { Dysplasia } \\
\text { Dysplasia } \\
1^{\circ} \\
\text { Dysplasia } \\
\text { Varus tilt } \\
\text { Varus tilt } \\
\text { Dysplasia }\end{array}$ & $\begin{array}{r}-3.6 \\
+32.0 \\
+\quad 5.2 \\
+\quad 1.8 \\
+\quad 8.7 \\
+\quad 3.9 \\
+\quad 7 \cdot 1 \\
+\quad 3.2 \\
-12.3\end{array}$ & $\begin{array}{l}0 \\
0 \\
0 \\
+ \\
0 \\
0 \\
0 \\
0 \\
0\end{array}$ & $\begin{array}{l}69 \\
66 \\
40 \\
55 \\
65 \\
58 \\
54 \\
57 \\
43\end{array}$ & $\begin{array}{l}- \\
- \\
- \\
- \\
- \\
-\end{array}$ \\
\hline
\end{tabular}




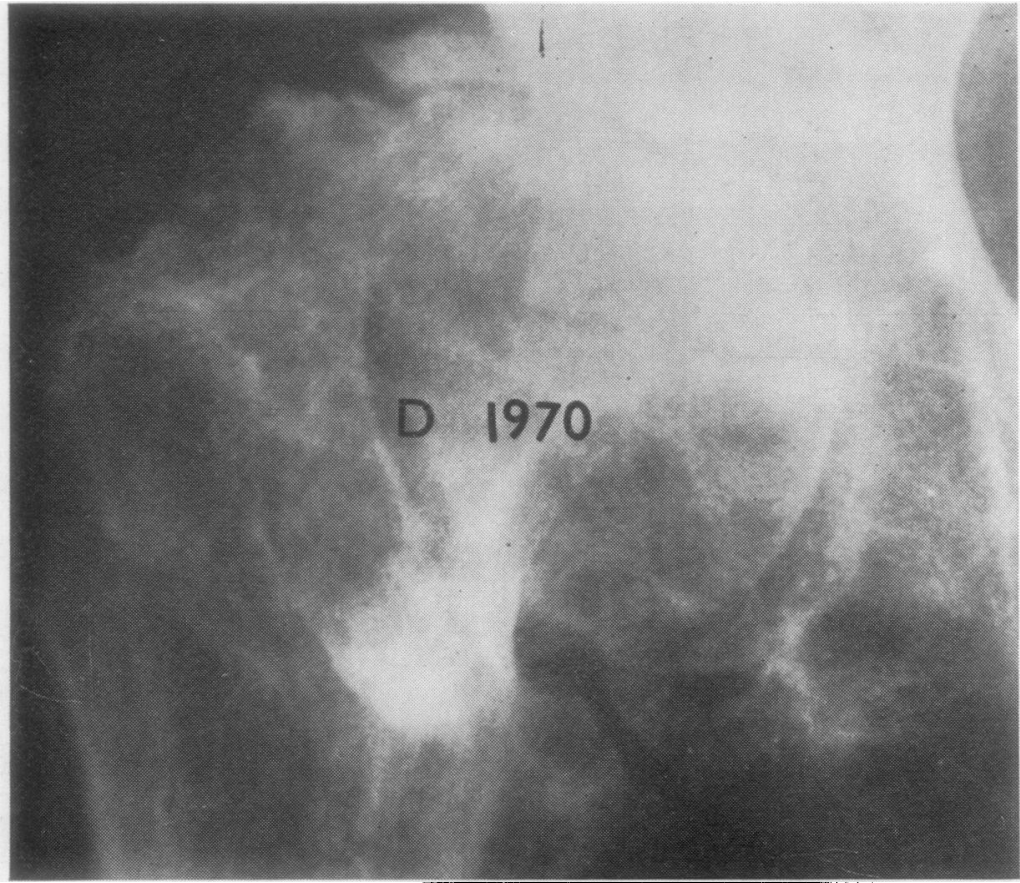

FIG. 5 Hip 1

FIG. 6 Hip 1

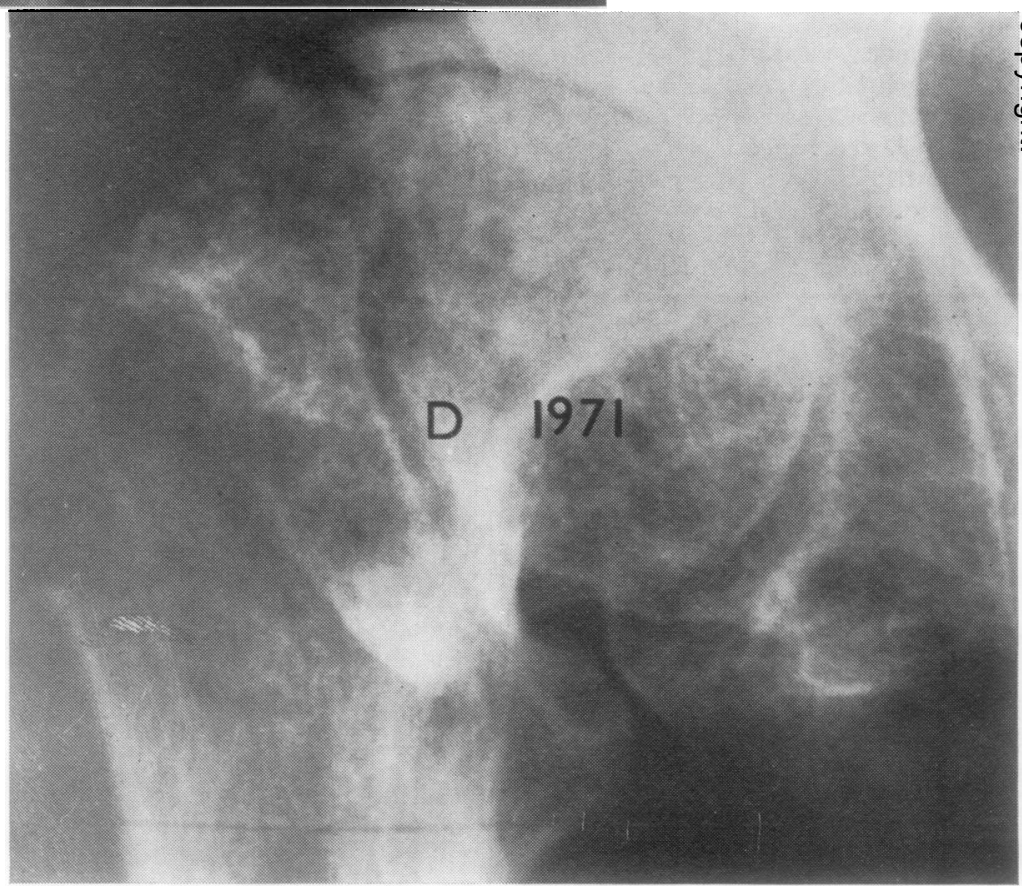

Joint space recovery occurred on average 10 years from the onset of symptoms. The progressive group were, on average, followed for a longer period than this (14 years).

Pain (Table II) was assessed at each attendance; there were, however, two patients who were $x$-rayed but for whom adequate clinical details were not available. Only three of twelve patients in the recovery group ( 25 per cent.) complained of persistent pain compared with six of nine patients in the progressive group (67 per cent.).

Table III shows that the recovery group took less analgesics than the progressive group (17 compared with 75 per cent.) Phenylbutazone or indomethacin 
FIG. 7 Hip 4

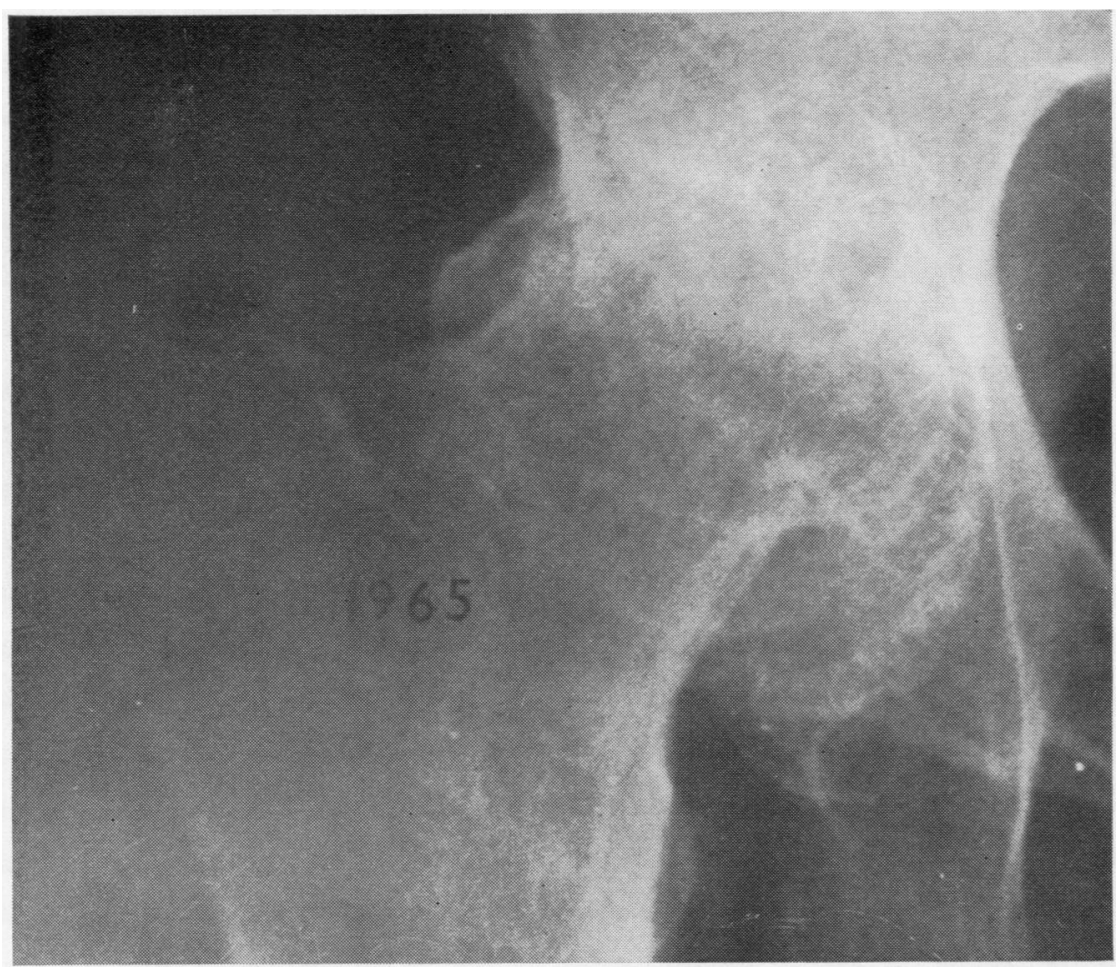

Table II Incidence of Pain

\begin{tabular}{|c|c|c|c|}
\hline \multicolumn{2}{|c|}{ Group } & \multirow[t]{2}{*}{$I$} & \multirow{2}{*}{$\frac{I I}{9}$} \\
\hline No.o & ips & & \\
\hline Pain & $\begin{array}{l}\text { None } \\
\text { Occasional } \\
\text { Persistent }\end{array}$ & $\begin{array}{l}3 \\
6 \\
3 \text { ( } 25 \text { per cent.) }\end{array}$ & $\begin{array}{l}0 \\
3 \\
6 \text { (67 per cent.) }\end{array}$ \\
\hline
\end{tabular}

Table III Analgesic intake

\begin{tabular}{|c|c|c|}
\hline Group & $I$ & II \\
\hline No. of hips & 12 & 8 \\
\hline \multicolumn{3}{|l|}{ Analgesic intake } \\
\hline $\begin{array}{l}\text { Above minimal } \\
\text { level }\end{array}$ & 2 (17 per cent.) & $6(75$ per cent. $)$ \\
\hline Decreased & 5 & 0 \\
\hline Same & 6 & 7 \\
\hline Increased & 1 & 1 \\
\hline
\end{tabular}

* 1 patient excluded because of involvement of the opposite knee gave rise to major symptoms

did not appear to influence progress; both these antiinflammatory analgesic agents were used by patients in both groups to a comparable degree.

Table IV shows that the range of mobility increased or remained the same in 75 per cent. of the recovery group compared with 11 per cent. of the progressive group. Nevertheless, the range of movement in the recovery group was limited and 66 per cent. of these patients had a range of less than 1 .
Table IV Mobility

\begin{tabular}{|c|c|c|}
\hline Group & $I$ & $I I$ \\
\hline No. of hips & 12 & 9 \\
\hline \multicolumn{3}{|l|}{ Mobility } \\
\hline Increased & 2 & 0 \\
\hline Same & 7 & 1 \\
\hline Decreased & & 8 \\
\hline Range less than 1 & 8 (66 per cent.) & $4(44$ per cent \\
\hline
\end{tabular}

* Graded 0 to 3

The average weight of each group was comparable; Group I were $7 \cdot 2$ per cent. above their ideal weights compared with 4.7 per cent. in Group II.

It was interesting to note the higher prevalence of Heberden's nodes in Group I ( 50 per cent.) compared with only 11 per cent in Group II.

\section{Discussion}

The concept of a reconstructive process in osteoarthrosis was reported by Harrison, Schajowicz, and Trueta (1953), who referred to osteoclastic removal of necrotic bone and to osteogenesis within the pressure segment. They also stated that where the fibrous marrow came to the surface, it differentiated into fibrocartilage which at times was almost hyaline in nature. They thought that for the most part these sproutings of cartilage remained discrete, but 
FIG. 8 Hip 4

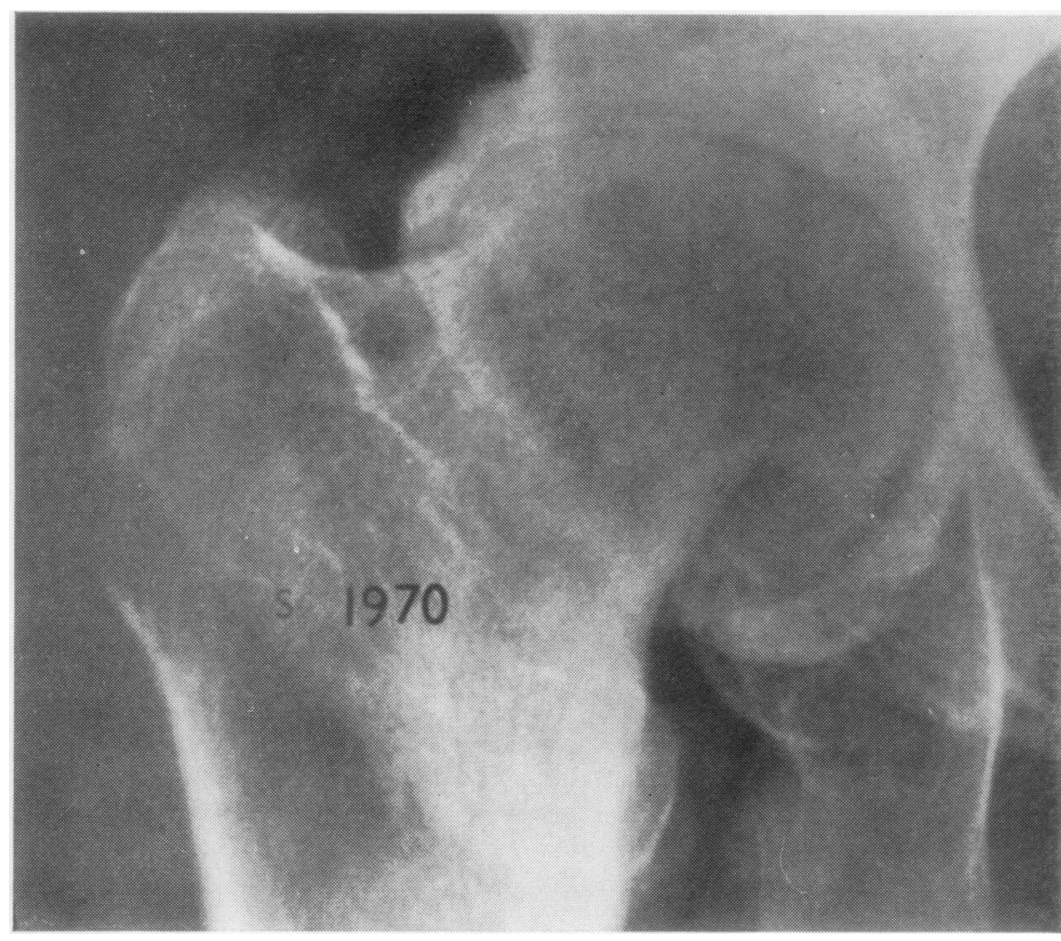

FIG. 9 Hip 13

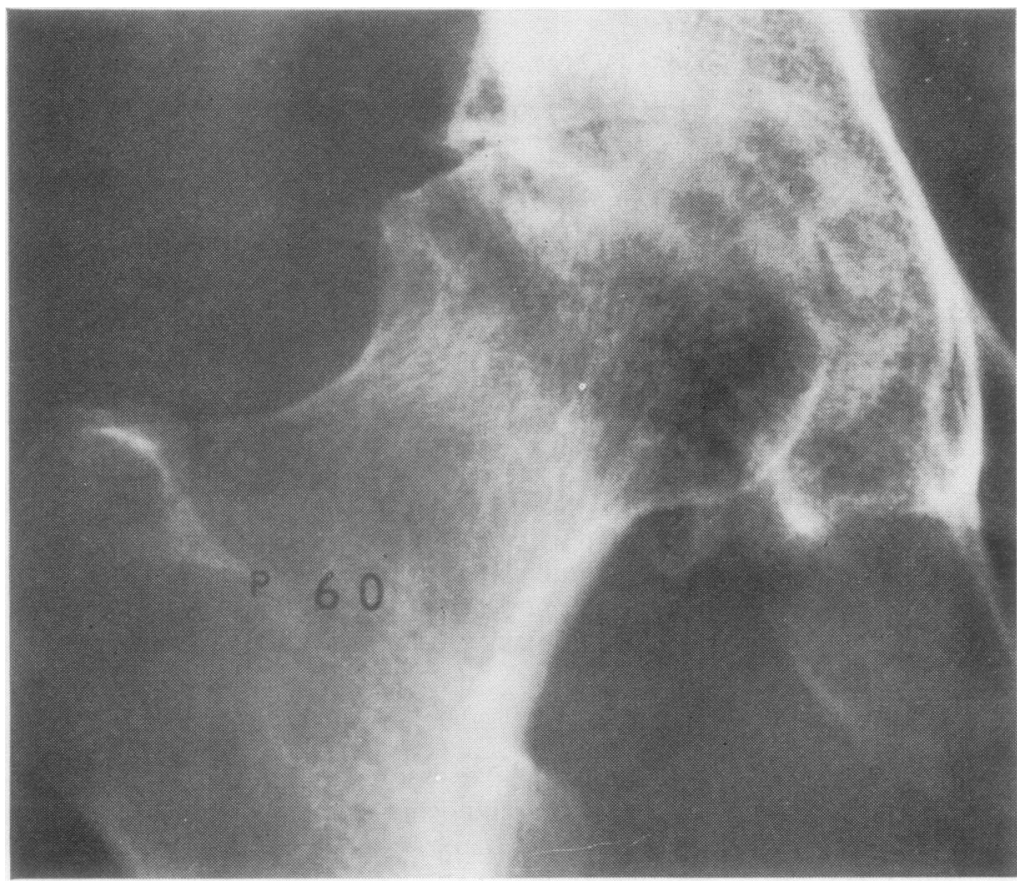

that in those patients whose hip joints are placed at rest or in which mechanical conditions have changed, the cartilagenous outgrowths became confluent and could resurface the previously naked bone.
It is considered that osteotomy effects a change in mechanical stress and that this brings about a recovery of the radiological joint space. The reasons for a spontaneous change in mechanical stress, however, would appear less obvious. In the patient 


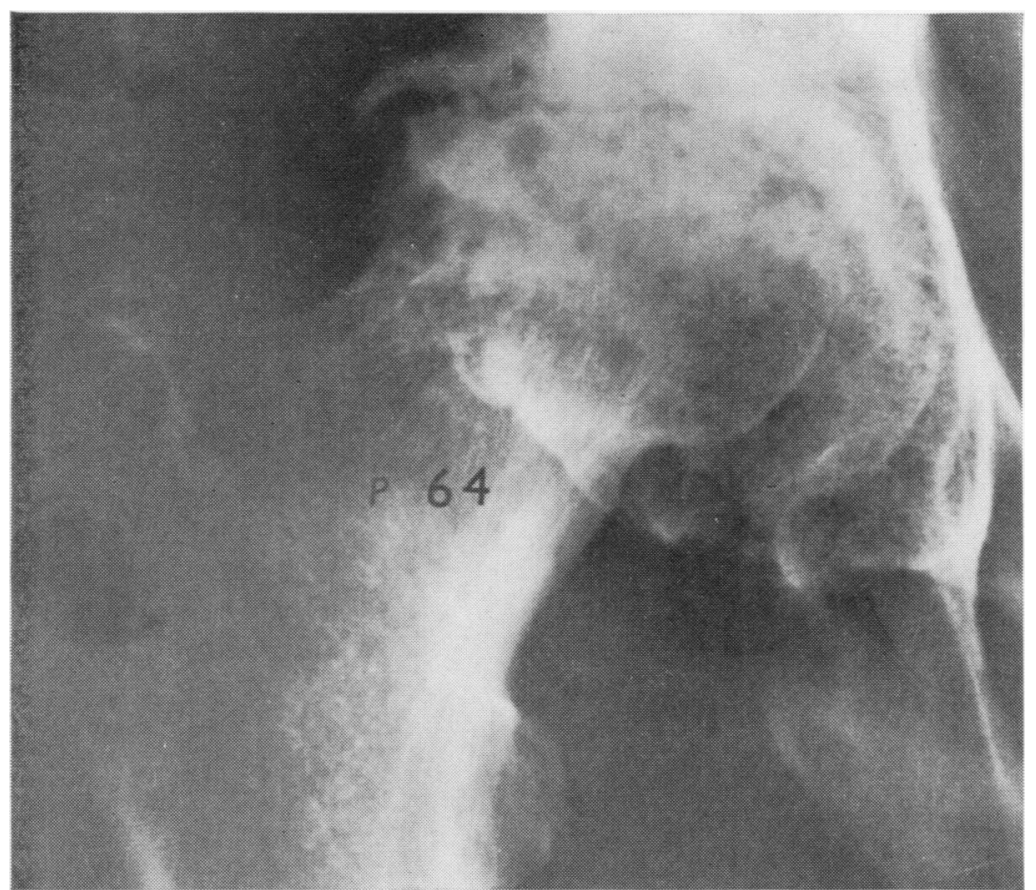

FIG. 10 Hip 13

reported by Storey and Landells (1971), the arthritic femoral head was found at necropsy to be clothed with fibrocartilage. They stated that frequent changes in stress and malalignment occurred as a part of the arthritic process and postulated that stabilization was necessary and was probably in the main provided by two large osteophytes.

All the cases in our recovery group showed substantial osteophyte formation. We consider that the time of arrest of the cystic destructive changes coincides with the stage when the retaining osteophytes become well established. The reparative process then steadily takes over. Could this be nature's osteotomy?

We believe that a prognosis based on $x$-ray changes is possible in cystic degenerative hip disease. Substantial retaining osteophytes favour joint recovery and a relatively pain-free and stable hip, but when osteophytes are small or absent the hip will probably deteriorate both radiologically and clinically. It may be that the presence of Heberden's nodes indicates that such osteophytes will develop.

\section{Summary}

A study into the natural course of hip osteoarthrosis was carried out; 28 patients (31 hips) with $x$-ray evidence of cystic changes were included and have been followed for 5 years or more. $X$-ray findings determined two major groups:

(I) Joint Space Recovery Group (14 hips). These showed stabilization of the hip and recovery of the joint space.

(II) Progressive Group (9 hips). These all deteriorated.

The recovery of the joint space in Group I, though not necessarily complete, appeared to depend on the establishment of adequate upper and lower pole 'retaining' osteophytes. Clinical findings in this group correlate favourably, especially with pain and analgesic intake, though hip movements tend to remain restricted.

We are deeply grateful to all who were involved in the Research Hip Clinic, in particular to Dr. Oswald Savage, O.B.E., M.D., F.R.C.P., whose original idea the clinic was. We should also like to thank Mrs. K. Gill, M.C.S.P., for her role in measurement and organization throughout the 10-year period and Dr. A. C. Boyle, for his continued interest.

Finally, we should like to express our gratitude to Dr. M. Corbett for her comments and advice.

\section{References}

Adam, A., AND SPENCE, A. J. (1958) J. Bone Jt Surg., 40B, 219 (Intertrochanteric osteotomy for osteoarthritis of the hip)

ARDEN, G. P. (1957) Ibid., 39B, 750 (Variations in joint space of the hip as shown radiographically)

DANielsson, L. G. (1964) Acta orthop. scand., Suppl. 66 (Incidence and prognosis of coxarthrosis)

Harris, N. H., AND KirwaN, E. (1964) J. Bone Jt Surg., 46B, 477 (Results of osteotomy for early primary osteoarthritis of the hip) 
Harrison, M., Schajowicz, F., and Trueta, J. (1953) Ibid., 35B, 598 (Osteoarthropathy of the hip: A study of the nature and evolution of the disease)

HiRSCH, C. (1960) Acta orthop. scand., 30, 129 (Intertrochanteric osteotomies in osteoarthritis of the hip)

Kellgren, J. H., and LaWrence, J. S. (1957) Ann. rheum. Dis., 16, 494 (Radiological assessment of osteoarthrosis)

Kemsley, W. F. F. (1952) Ann. Eugen., 16, 316 (Body weight at different ages and heights)

MurRAY, R. O. (1965) Brit.J. Radiol., 38, 810 (Aetiology of primary osteoarthritis of the hip)

Nissen, K. I. (1963) Proc. roy. Soc. Med., 56, 1051 (The arrest of early primary osteoarthritis of the hip by osteotomy)

Seifert, M., Whiteside, C. G., AND Savage, O. (1969) Ann. rheum. Dis., 28, 325 (A 5-year follow-up of fifty cases of idiopathic osteoarthritis of the hip)

Storey, G. O., AND Landells, J. W. (1971) Ibid., 30, 406 (Restoration of the femoral head after collapse in osteoarthrosis) 